\section{$\underset{\substack{\text { hommes } \\ \text { \& migrations }}}{ }$}

\section{Hommes \& migrations}

Revue française de référence sur les dynamiques

migratoires

1293 | 2011

L'immigration dans les musées

\title{
Fabienne Swiatly, Unité de vie
}

Lyon, La Fosse aux ours, 2011, 106 p., 15 euros

\section{Élisabeth Lesne}

\section{OpenEdition \\ 1 Journals}

\section{Édition électronique}

URL : http://journals.openedition.org/hommesmigrations/550

DOI : 10.4000/hommesmigrations.550

ISSN : 2262-3353

\section{Éditeur}

Musée national de l'histoire de l'immigration

\section{Édition imprimée}

Date de publication : 1 septembre 2011

Pagination : 162

ISSN : 1142-852X

\section{Référence électronique}

Élisabeth Lesne, «Fabienne Swiatly, Unité de vie », Hommes \& migrations [En ligne], 1293 | 2011, mis en ligne le 29 mai 2013, consulté le 22 septembre 2020. URL : http://journals.openedition.org/

hommesmigrations/550; DOI : https://doi.org/10.4000/hommesmigrations.550

Ce document a été généré automatiquement le 22 septembre 2020.

Tous droits réservés 


\title{
Fabienne Swiatly, Unité de vie
}

\author{
Lyon, La Fosse aux ours, 2011, 106 p., 15 euros
}

\section{Élisabeth Lesne}

\section{RÉFÉRENCE}

Fabienne Swiatly, Unité de vie, Lyon, La Fosse aux ours, 2011, 106 p., 15 euros

1 Un titre aux connotations mystérieuses. Un auteur qu'on ne voit pas sur les plateaux de télévision. Seulement 106 pages d'un petit format, mais à le lire un crayon à la main, on a envie de tout souligner, tant ce livre touche à l'intime et à l'universel, puisqu'il parle des failles de la mémoire, de la peur de l'ennui et des maisons de retraite.

"Qu'est-ce que tu me racontes de beau aujourd'hui ?", demande à sa belle-fille une vieille dame atteinte de la maladie d'Alzheimer.

3 Fabienne Swiatly raconte avec un sobre réalisme les visites dans un établissement médicalisé, l'énergie qu'il faut emmagasiner avant, et le besoin vital de remettre le monde en mouvement, après. "La vie avec le moins de bruit possible", "une tenue blanche qui salue poliment et rappelle que la vieillesse est devenue une maladie", "des odeurs chaudes de nourriture, d'excréments et de produits de nettoyage", et surtout, pour le visiteur, l'espoir de ne pas finir comme ça, dans le calme, "oubliant la promesse déjà faite à l'adolescence de se suicider avant quarante ans".

4 Sinistres, ces pages? Non, juste le courage de regarder en face ce qu'on appelle "l'accompagnement de fin de vie" et l'intérêt de découvrir l'évolution de la relation entre ces deux femmes, grâce à des chapitres qui racontent "la vie d'avant". Adulte, difficile de se comporter comme le petit-fils ado qui déclare: "Non, je ne reviendrai plus. Ça sert à rien, elle ne se souvient plus de moi."

5 La belle-fille, réfugiée bosniaque, a aussi des problèmes avec la mémoire. Elle regrette qu'on ne l'interroge jamais sur la guerre de l'ex-Yougoslavie que les Français trouvent déjà si lointaine et si complexe, alors qu'ils l'ont suivie en direct à la télévision. Mais comment parler de son pays quand on est une survivante, quand on a laissé dans la 
forêt de Visegrad sa mère, son père et son frère ? Photographe professionnelle, grâce à l'ordinateur, elle introduit de la violence dans les lotissements trop tranquilles et tous semblables de la province française: "J'ajoute un impact de balle dans le pastel des murs ou le plastique des chaises, un jouet explosé près du portique à jeux. (...) Le reflet d'une arme dans la fenêtre." Et alors qu'elle feuillette les albums photo de la famille avec la vieille dame, elle laisse les clichés de ses parents perdus enfermés dans une enveloppe.

6 La maladie - la vieillesse ? - réserve quelques surprises : Elle "a levé les interdits d'une éducation stricte où ni la joie ni les peines ne pouvaient s'exprimer". Dans ce lieu aseptisé, la jeune femme se sent plus proche de sa belle-mère avec laquelle elle n'avait eu que des rapports convenus. À présent, des gros mots surgissent dans les propos de la vieille dame ainsi qu'une liberté d'esprit jusqu'alors inconnue. La visiteuse lui tient la main et remarque : "On ne peut pas exister si on n'est pas touché." Quant à l'ennui ressenti parfois au cours des visites, est-il pire que celui des dimanches après-midi dans la maison de campagne de la belle-famille, pire que "'obsession de vouloir mettre les corps au repos"?

7 Insuffler de la vie même là où elle est si ténue, c'est la condition, comme dit Fabienne Swiatly, pour "mourir vivant". 